\title{
Feasibility Design Study of Long Life BWR with Natural Uranium/Thorium as Fuel Cycle Input
}

\author{
Zaki Su'ud ${ }^{1)}$, Rijal Kurniadi ${ }^{1)}$, Rida SNM ${ }^{2)}$, and Zuhair ${ }^{3)}$ \\ 1) Nuclear and Biophysics Research Division, \\ Faculy of Mathematics and Natural Sciences, \\ Bandung Institute of Technology, \\ Jl. Ganesha 10, Bandung, Indonesia \\ ${ }^{2)}$ Doctoral Student, Dept. Nuclear Engineering, Kyushu University, Japan \\ 3) PTRKN BATAN Kompleks Puspitek Serpong \\ e-mail: szaki@fi.itb.ac.id
}

\begin{abstract}
Feasibility design study of Long Life BWR with natural uranium/thorium as fuel cycle input has been performed. The reactor core is divided into 6 equal regions in radial direction. The fresh fuel is first loaded into the most outer region then shifted to the center of the core, and from there shifted to the nearby region in the outward direction. Nitride fuel is employed in the core to get better criticality and conversion/breeding ratio. The results show that uranium fuel combined with low moderating ratio environment is superior to make the system critical.
\end{abstract}

Keywords: Long life, BWR, Uranium cycle, Thorium cycle, Criticality

\section{Introduction}

The utilization of natural uranium and thorium is important to keep the optimal nuclear energy resources. On the other hand nuclear fuel enrichment and nuclear fuel reprocessing which is needed to use nuclear energy using current technology are very sensitive issues related to the nuclear non-proliferation in the world especially when it is carried out in the developing countries. Long life reactor without on-site refuelling based on uranium or thorium fuels are an example of method to more efficently utilize these fuels ${ }^{1-11)}$

In the previous works, liquid metal cooled long life fast reactor which can be continuously operated by only supplying natural uranium without fuel enrichment plant or fuel reprocessing plant has been confirmed possible ${ }^{12-15}$ ). Combined with high neutronic and safety performance such reactors have good prospects in the future. However the dominant current commercial Nuclear Power Plant (NPP) are based on water cooled system.

Therefore, in this paper feasibility design study of long life tight lattice BWR reactors which can be continuously operated by only supplying natural uranium without fuel enrichment plant or fuel reprocessing plant is investigated. Using such type of NPPs optimum nuclear energy utilization including in developing countries can be easily conducted without the problem of nuclear proliferation.

\section{Design Concept and Calculation Method}

In this study the following design concept are adopted. The active core is subdivided into 6 sub region in radial direction (see Figure 1 ) and reflector is put in the the most outer region. The fresh fuel is initially put in region 5 , then shifted to region 6 , and after that shifted to regions $1,2,3$ and then 4 . Region 7 is filled with reflector (mainly water). Nitride fuel is employed to provide high density fertile and fissile material in the core.

\begin{tabular}{|l|l|l|l|l|l|l|}
\hline Reg. 1 & Reg. 2 & Reg. 3 & Reg. 4 & Reg. 5 & Reg. 6 & Reg. 7 \\
Third & Fourth & Fifth & Sixth & First & Second & Reflector \\
shift & shift & shift & shift & shift & shift & \\
\hline
\end{tabular}

Figure 1. Shuffling scheme

The calculation method can be described as follows. The calculation is started by guessing power density in each region, then cell burn-up calculation is performed using SRAC code system. Then multigroup diffusion calculation is performed using FIITBCH1 code and the resulted power density distribution is taken as feedback for cell calculations. The iteration is performed till convergence condition is reached $^{12-14)}$

\section{Calculation Results and Discussion}

The Tables 1 and 2 show the parameters of calculated cores. In this paper we present 4 type BWR core, first using thorium cycle while others using uranium cycle. In order to get high conversion/breeding high void fraction coolant is selected which in general give relatively fast spectrum. The calculation results are shown in Figures 2-13. Figure 2 shows Keff pattern change during burnup for case A (Th cycle) and it shows that the system is subcritical. It means that for thorium cycle current core configuration is not possible to make long life reactor which fuel cycle input is thorium only (without additional U-233 or U-235). Figure 3 shows Kinf change during burn-up for case A. It shows that in some burn-up period the Kinf value becomes more than 1.0 but the value is too small to make the whole core critical. The average burn-up level of the fuel is nearly 350000MWd/tonHM. 
Table 1. General Reactor Parameter

\begin{tabular}{|l|c|}
\hline \multicolumn{1}{|c|}{ Parameter } & Value/description \\
\hline Power (MWth) & $2200-3500$ \\
\hline $\begin{array}{l}\text { Number of equal volume region } \\
\text { in core }\end{array}$ & 6 \\
\hline Sub cycle length (years) & 10 \\
\hline Fuel type & Nitride (UN-PuN) \\
\hline Fuel volume fraction & $60 \%$ \\
\hline Cladding vol. fraction & $12.5 \%$ \\
\hline Coolant volume fraction & $27.5 \%$ \\
\hline Fuel diameter & $1.2 \mathrm{~cm}$ \\
\hline Coolant type & $\mathrm{H}_{2} \mathrm{O}$ \\
\hline $\begin{array}{l}\text { Radial width of first (central) } \\
\text { region }\end{array}$ & $70 \mathrm{~cm}$ \\
\hline Axial reflector width & $70 \mathrm{~cm}$ \\
\hline Radial reflector width & $70 \mathrm{~cm}$ \\
\hline Active Core Radius & $171.5 \mathrm{~cm}$ \\
\hline
\end{tabular}

Table 2 Specific parameter for each core type

\begin{tabular}{|c|c|c|c|c|}
\hline $\begin{array}{c}\text { Core } \\
\text { Type }\end{array}$ & $\begin{array}{c}\text { Power } \\
\text { MWt }\end{array}$ & $\begin{array}{c}\text { Active } \\
\text { Core } \\
\text { Height } \\
\text { (cm) }\end{array}$ & $\begin{array}{c}\text { Void } \\
\text { Fraction } \\
(\%)\end{array}$ & Note \\
\hline A & 2200 & 200 & 99 & Thorium cycle \\
\hline B & 3000 & 250 & 98 & Uranium cycle \\
\hline C & 3000 & 250 & 95 & Uranium cycle \\
\hline D & 3200 & 250 & 97.5 & Uranium cycle \\
\hline
\end{tabular}

Figures 4 and 5 show Keff and Kinf pattern change during burn-up for case B (U cycle with very high void fraction). It is shown that the system is critical with enough margin of Keff, and during burnup the value of Keff continuously increases. The kinf value is more than 1.0 for more than half of the burnup period. The average burn-up level of the fuel in this case is nearly $370000 \mathrm{MWd} /$ tonHM.

Figures 6 and 7 show Keff and Kinf pattern change during burn-up for case C (U cycle with 95\% void fraction). It is shown that the system is critical with small margin of Keff, and during burn-up the value of Keff also continuously increases. The kinf value is more than 1.0 for more than half of the burnup period but the maximum value is still lower than that of case B. The kinf value is more than 1.0 for more than half of the burn-up period. The average burn-up level of the fuel in this case is nearly 365000MWd/ton HM.

Figures 8 and 9 show Keff and Kinf pattern change during burn-up for case $\mathrm{D}$ (U cycle with $97.5 \%$ void fraction). It is shown that the system is critical with enough margin of Keff, and during burnup the value of Keff also continuously increases. The kinf value is more than 1.0 for more than half of the burn-up period but the maximum value is still lower than that of case B. The kinf value is more than 1.0 for more than half of the burn-up period which is slightly larger than that of case B but higher than that of case C. The average burn-up level of the fuel in this case is nearly 400000MWd/ton HM as shown in Figure 10.

Figure 11 shows radial power distribution at the beginning of life of case $\mathrm{D}$. It is shown that the core becomes very active just after entering region 2 (after half of overall burn-up process). Figure 12 shows conversion ratio change during burn-up. As burn-up proceed the conversion ratio continuously decreases due to decreasing number of fissile material and increasing number of fissile material especially at the first half of burn-up period. This is shown in Figures 13-14.

From the above results it can be seen that the neutron spectrum has important role in this system. Higher void ratio means harder spectrum that give higher conversion/breeding ratio so that natural uranium/thorium can be transformed into fissile material more effectively.

The burn-up level up to $400000 \mathrm{MWd} /$ ton or about $40 \% \mathrm{HM}$ show that the natural uranium/thorium fuel can be utilized optimally without fuel cycle facilities but the material problem becomes important.

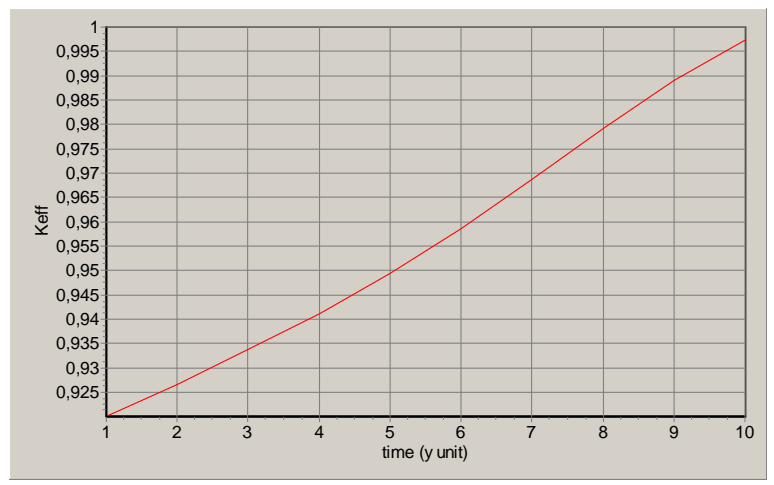

Figure 2. Keff change during burn-up for case A

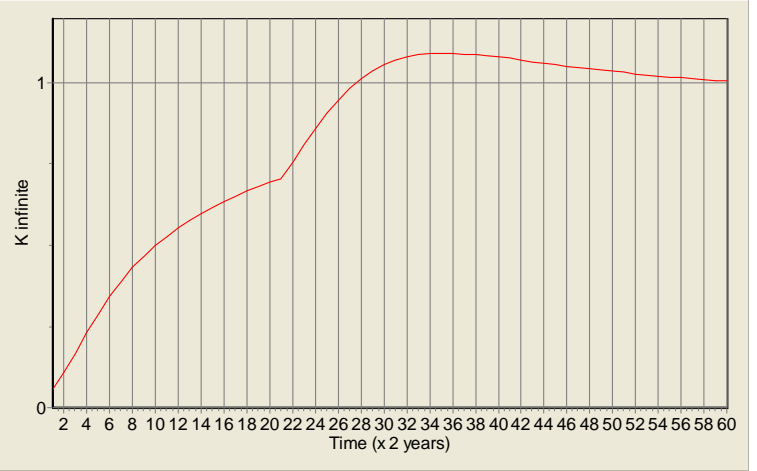

Figure 3. Kinf change during burn-up for case A

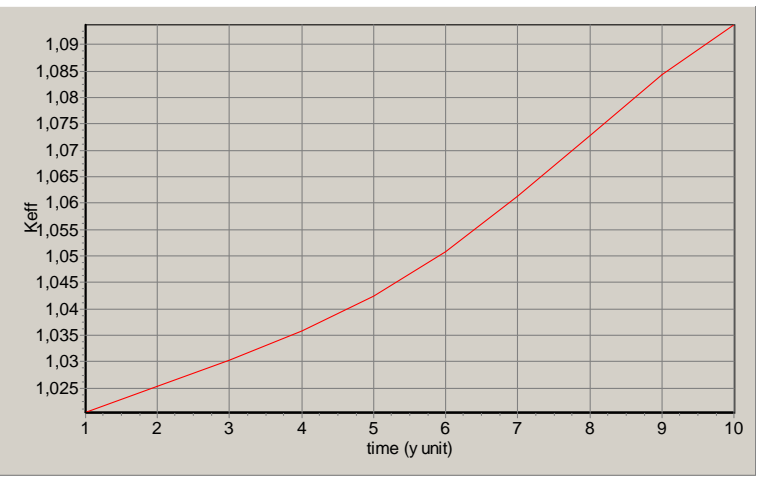

Figure 4. Keff change during burn-up for case B 


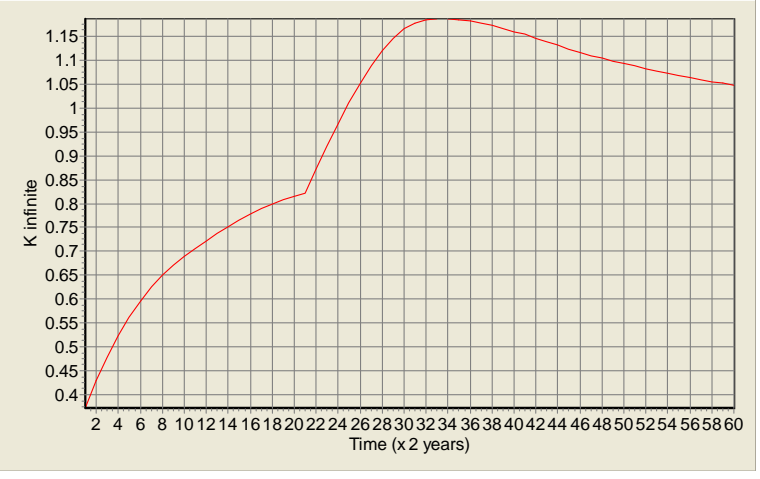

Figure 5. Kinf change during burn-up for case B

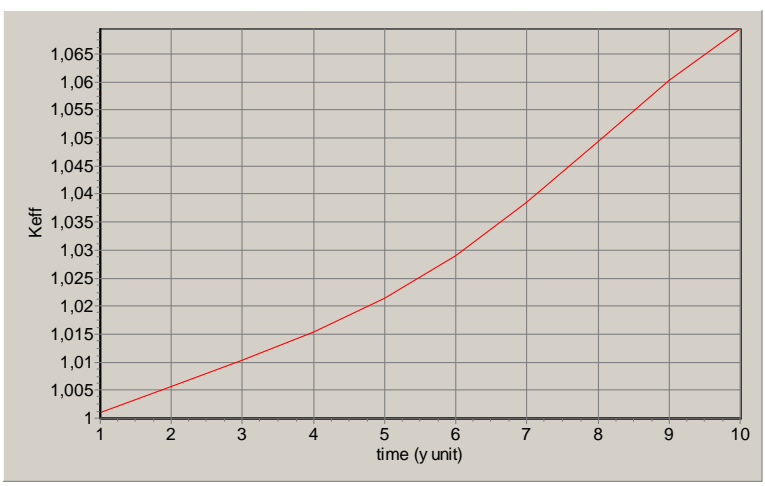

Figure 6. Keff change during burn-up for case C

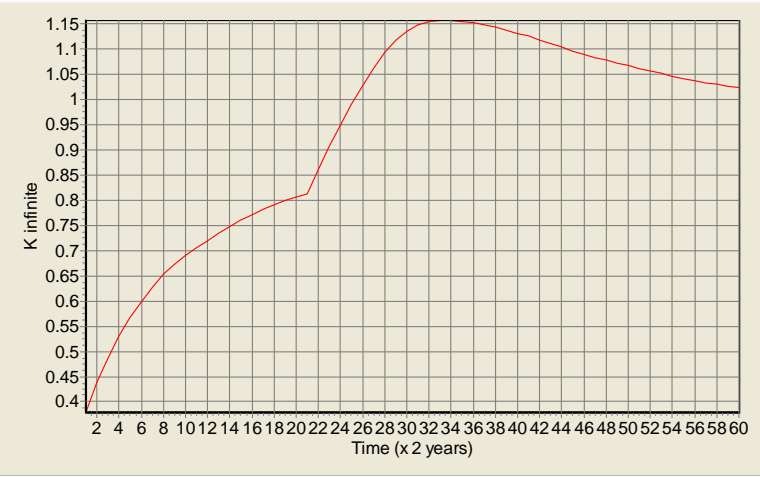

Figure 7. Kinf change during burn-up for case C

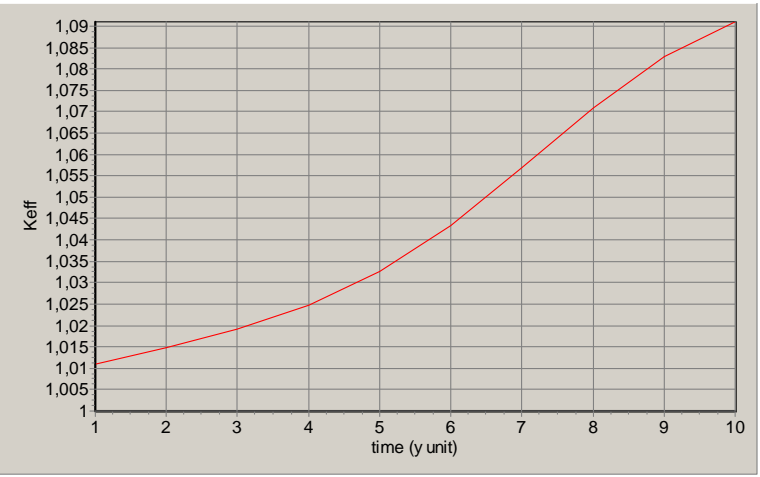

Figure 8. Keff change during burn-up for case D

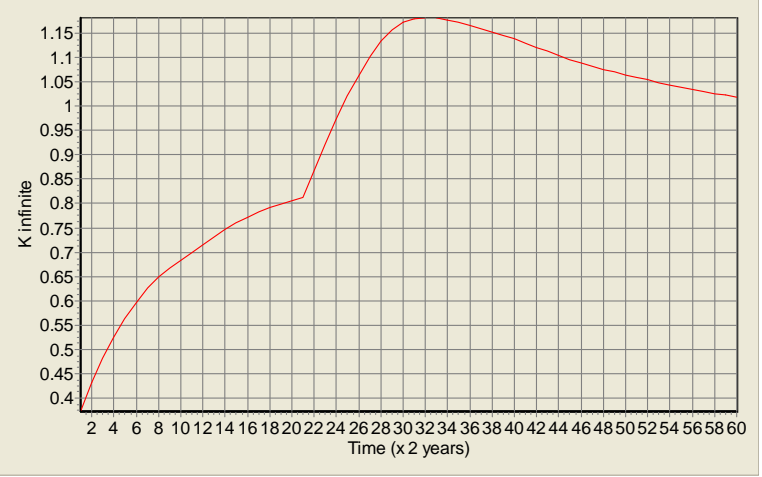

Figure 9. Kinf change during burn-up for case D

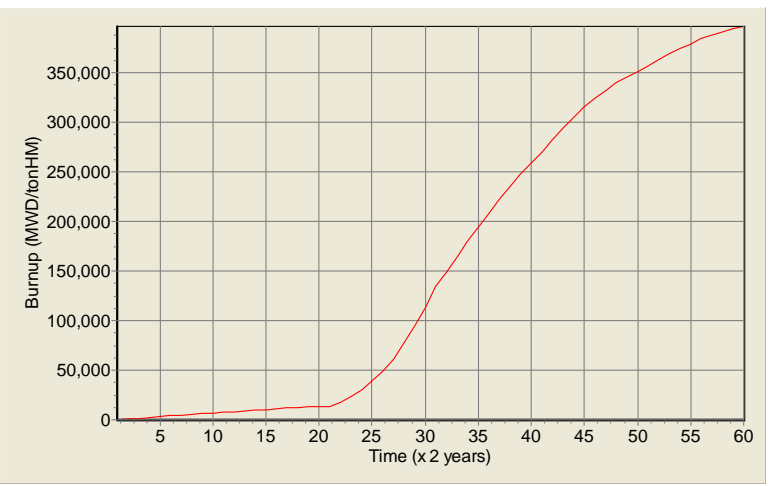

Figure 10. Burn-up history for case D

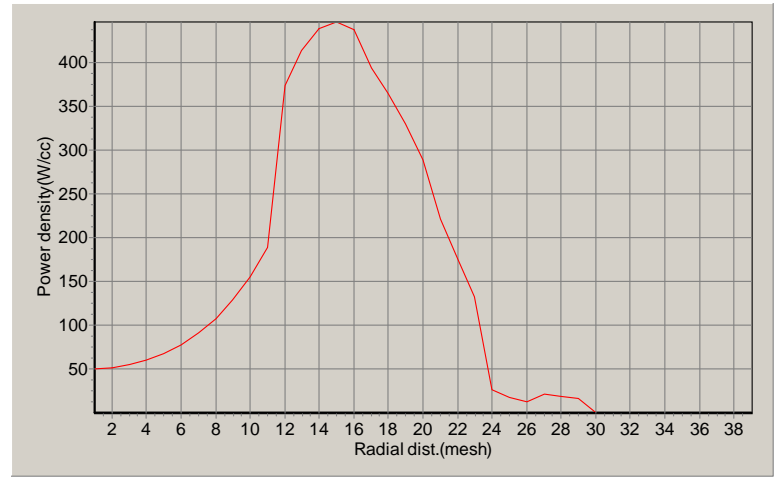

Figure 11. Radial power density distribution at the center for case D (BOL)

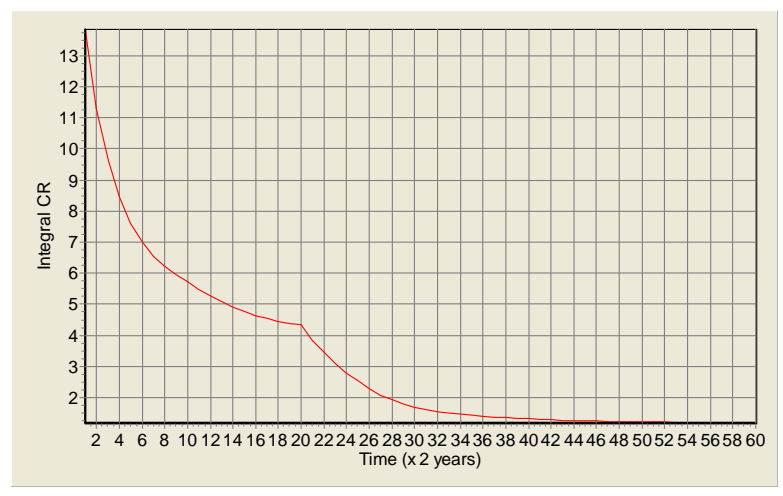

Figure 12. Conversion ratio change during burn-up for case D 


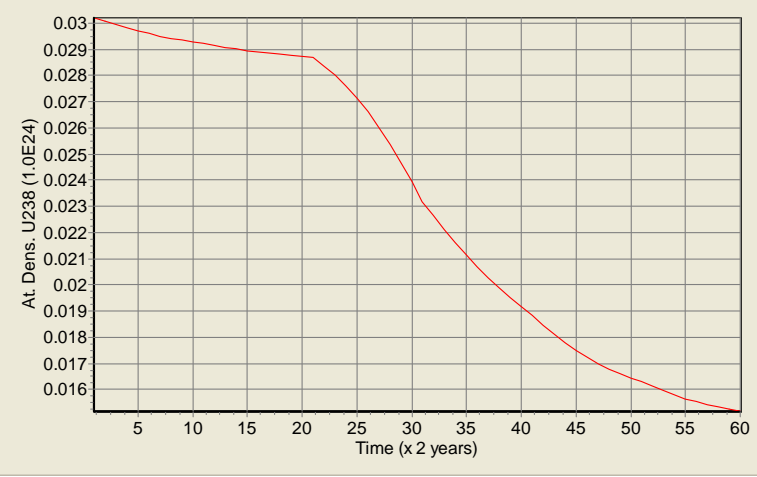

Figure 13 U-238 atomic density change during burnup for case D

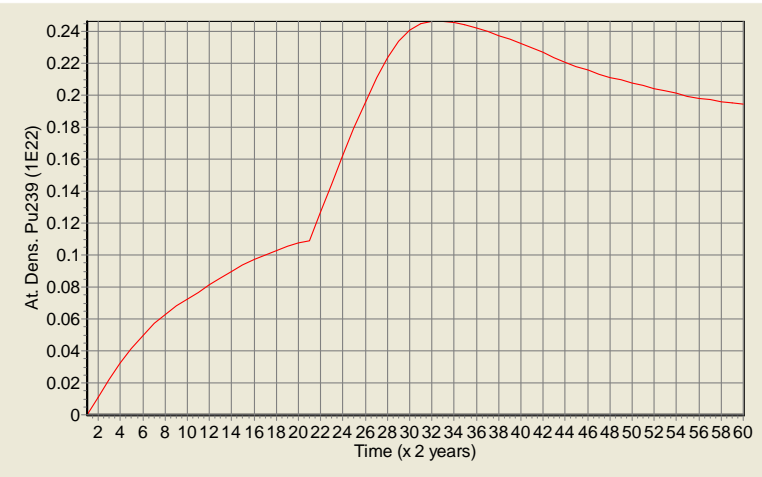

Figure 14 Pu-239 atomic density change during burnup for case D

\section{Conclusion}

Feasibility design study of Long Life BWR with natural uranium/thorium as fuel cycle input has been performed and the results show that uranium fuel combined with high void fraction environment is superior to make the system critical. Thorium cycle can not make the system critical under current condition. The resulted burnup level is about 350000$400000 \mathrm{MWd} /$ tonHM, and special material is needed.

\section{References}

1. Yuli Astuti and Zaki Su'ud, Preliminary Design Study of 40-100MWth Small Pressurized Water Reactor Using Thorium-uranium Based Fuel, Tokyo Tech COE INES Indonesia Conference, Bandung, March 2-4, 2005.

2. M. Nurul Subkhi and Zaki Su'ud, Design Study of Small Long-Life Thorium-Uranium Fueled Pressurized Water Reactor (PWR), Tokyo Tech COE INES Indonesia Conference, Bandung, March 2-4, 2005.

3. Eka Sapta Riyana and Zaki Suud, Design Study of Thorium Cycle Based Tight Lattice Long Life BWR, Proceeding of GLOBAL 2005 Conference, October 9-13, Tsukuba 2005.
4. T. Setiadipura et al., Neutronic Design Study of Small Long Life PWR with (Th,U) $\mathrm{O}_{2}$ fuel, Proceeding of GLOBAL 2005 Conference, October 9-13, Tsukuba 2005.

5. Dwi Irwanto and Zaki Su'ud, Design Study of Long Life Thorium Based PWR Using Annular Fuel Pin and Pa-231 as Burnable Poisson, Asian Physics Seminar 2005, Bandung, Indonesia, December 7-8, 2005.

6. Eka Sapta Riyana and Zaki Su'ud, Preliminary Design Study of Thorium and Protactinium Based Fuel for Long Life BWR, Asian Physics Seminar 2005, Bandung, Indonesia, December 7-8, 2005.

7. Muh. Nurul Subkhi and Zaki Su'ud, Preliminary Study of Small Long-Life PWR Core with Thorium Protactinium Fuelled, Asian Physics Seminar 2005, Bandung, Indonesia, December 78, 2005.

8. Iyos Subki et al., The Utilization of Thorium for Long Life Small Thermal Reactors Without OnSite Refueling, Progress of Nuclear Energy, 50, p. 152-156, 2008.

9. Zaki Su'ud, Comparative Study on Safety Performance of Nitride Fueled Lead-Bismuth Cooled Fast Reactor with Various Power Level, Progress of Nuclear Energy, 32:3/4 pp. 571 577, 1998.

10. Zaki Su'ud, Neutronic Performance Comparation of MOX, Nitride and Metallic fuel based 25-100 MWe Pb-Bi Cooled Long Life Fast Reactors without on site Refuelling, Progress of Nuclear Energy, 50, p. 276-278, 2008.

11. Zaki Su'ud, Safety Performance Comparation of MOX, Nitride and Metallic fuel Based 25-100 MWe Pb-Bi Cooled Long Life Fast Reactors without on site Refuelling, Progress of Nuclear Energy, 50, p. 157-162, 2008.

12. Zaki Suud et al., Design Study of Long Life PbBi Cooled Fast reactors Which Need Natural Uranium as Input Fuel Cycle, IAEA RCM Meeting, Vienna 4-8 Juni 2007.

13. Rida SNM and Zaki Su'ud, Design Study of PbBi Cooled Fast Reactors Which Fuel Cycle Input is Natural Uranium, Internatinal Journal of Nuclear Energy Science and Technology (IJNEST) 4:3, p 217-222, 2009.

14. Zaki Suud et al., Design Study of CANDLE Scheme Based Long Life Reactors With Input Fuel Cycle is Natural Uranium, Proceeding ICANSE 2007, 13-14 November 2007, Bandung, Indonesia.

15. H. Sekimoto and A. Nagata, "CANDLE" Burnup Regime After LWR Regime, Progress of Nuclear Energy, 50, p.109-113, 2008. 